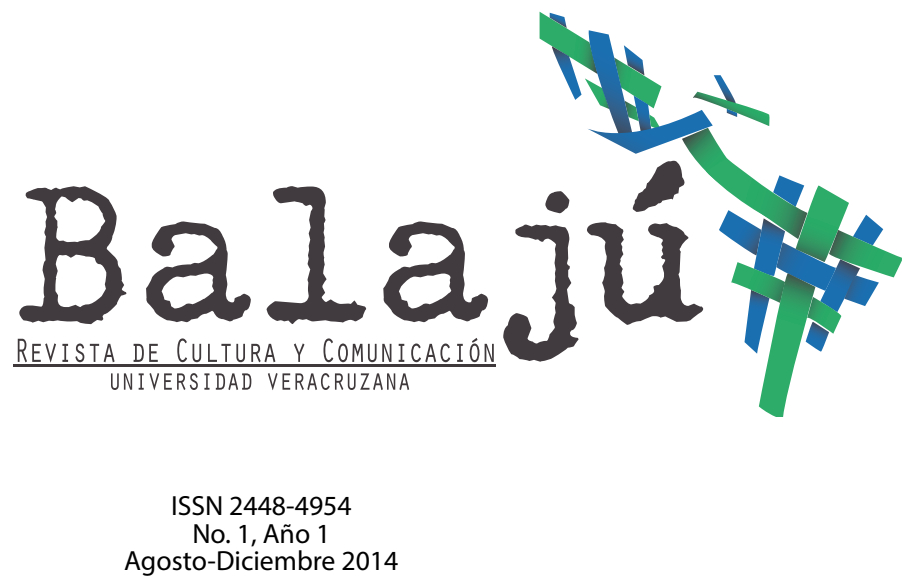

\title{
La significación del nombre
}

\section{Norma Esther García Meza* y Daniel Domínguez Cuenca** \\ Universidad Veracruzana, México}

*Doctora en Letras por la UNAM. Profesora-investigadora de tiempo completo en el Centro de Estudios de la Cultura y la Comunicación, Universidad Veracruzana.

**Doctor en Letras por la UNAM. Es responsable del proyecto Reflexionario Mocambo, espacio de producción, investigación y reflexión que explora las fronteras entre la palabra, el acto y la imagen con identidad regional, en la USBI-Veracruz, de la Universidad Veracruzana.

\section{RESUMEN}

En el presente artículo nos ocupamos de analizar el nombre como portador de memoria, representaciones e imaginarios, a partir de un conjunto de planteamientos teóricos acerca de la cultura y algunos de sus componentes: el lenguaje, la memoria, la otredad. Nuestras exploraciones parten de la interrogante: qué hay detrás del nombre que no se nombra, a la que nos invita un verso de Jorge Luis Borges. Así, hemos reunido un conjunto de testimonios para ilustrar que más allá del significado lingüístico y etimológico que el nombre pueda tener, lo que resuena en él es la memoria de los otros

\begin{abstract}
In the present paper we occupy ourselves with analyzing names as a means to transport memory, representations and imagery starting from a group of theoretical propositions about culture and some of its components: language, memory and the otherness. Our explorations come from a question to which Jorge Luis Borges invites us in a verse: what is there behind the name that is not spoken? Thusly, we have compiled a group of testimonies to illustrate that further from the linguistic and etymological significance that a name may have, what resonates in it is the memory of other names.
\end{abstract}

\section{PALABRAS CLAVE / KEYWORDS}

nombre, significación, lenguaje, memoria, otredad.

name, significance, language, memory, otherness. 


\section{La significación del nombre \\ Por Norma Esther García Meza}

\section{Presentación}

En el presente artículo nos ocupamos de analizar el nombre como portador de memoria, representaciones e imaginarios, a partir de algunos conceptos derivados de las aportaciones teóricas de diversos autores (Lotman, Bajtín-Voloshinov, Bachelard, Bourdieu, Ricoeur, Zemelman, entre otros), que han guiado nuestras indagaciones en el territorio de los estudios literarios. Se trata de un conjunto de planteamientos acerca de la cultura y algunos de sus componentes: el lenguaje, la memoria, la otredad, que nos permiten aproximarnos a la significación del nombre. No nos referiremos, por tanto, al nombre como derecho humano, ni abundaremos en su carácter lingüístico ${ }^{1}$ o etimológico y tampoco abordaremos las discusiones en torno a su sentido destinal ni las controversias políticas, jurídicas y éticas actuales acerca de su restitución cuando ha sido cambiado o negado ${ }^{2}$ : temas que, sin duda, están asociados a la problemática del nombre y frente a los cuales estamos en deuda. A continuación presentamos el resultado de nuestras exploraciones.

\section{Signo, samblaje y memoria}

a) El nombre como signo

"Conoces el nombre que te dieron, no conoces el nombre que tienes".

Libro de las evidencias José Saramago

En el Diccionario de uso del español, María Moliner define al nombre como aquella "Palabra (o palabras, si el nombre es compuesto) que precede a los apellidos en el nombre completo de una persona y con la que se la distingue dentro de la familia" (Moliner, 2007). Conocido también como "nombre de pila" el nombre está asociado al "prestigio o buena fama que alguien tiene entre la gente" (Moliner, 2007). Es decir, el nom-

1.- Ver Elena Bajo Pérez, El nombre propio en español, Arco Libros, Madrid, 2008.

2.- En el capítulo "Terrorismo de estado en Argentina y niños secuestrados por el poder militar (1976-1983)", Juan Eduardo Tesone le dedica un apartado al robo de la identidad de estos niños y, además de analizar las consecuencias psicológicas, aporta datos sobre algunas de las controversias jurídicas actuales en torno a la restitución de su identidad y a la recuperación de sus nombres y apellidos. (Tesone, 2009: 149-166). Como ejemplo de las problemáticas políticas y éticas asociadas a la restitución de la identidad sugerimos los siguientes sitios: https://www.youtube.com/watch?v=U14QEqaSF-Y y https://www.youtube.com/watch?v=BcHZZLQcN0k (consultados el 2 de septiembre de 2014). 
bre distingue a los sujetos pero también los hace parte de una comunidad. Y es, precisamente, en ese transitar de lo individual a lo social y viceversa como el nombre se va saturando de significaciones convirtiéndose, así, en el signo más enganchado a la realidad, tal como lo concibe Iuri M. Lotman: "los nombres propios [son] (indiscutiblemente, el signo más enganchado a la realidad)" (Lotman, 1996: 37).

El signo es un producto ideológico que está formado por opiniones, valoraciones, puntos de vista y sentidos diversos que los sujetos le imprimen como parte de la interacción que establecen dentro de la esfera sociocultural: "El signo, gracias a su carácter neutral y compartido por todos los grupos sociales, es la arena de la lucha de clases, porque en su territorio se cruzan las opiniones, valoraciones, posturas ideológicas y existenciales, que provienen de los sujetos organizados en clases sociales" (Bubnova, 1996: 35). Para que el signo se produzca, dice M. Bajtín-Voloshinov, es necesario que los sujetos "estén socialmente organizados, que representen un colectivo: sólo entonces puede surgir entre ellos un medio sígnico (semiótico o portador de significación)" (Voloshinov, 1993: 35-36).

Uno de los signos cuya importancia es decisiva para la comunicación entre los sujetos socialmente organizados es la palabra: "La palabra es el fenómeno ideológico por excelencia. Toda la realidad de la palabra se disuelve por completo en su función de ser signo. En la palabra no hay nada que sea indiferente a tal función y que no fuese generado por ella. La palabra es el medio más puro y genuino de la comunicación social" (Voloshinov, 1993: 37).

La palabra nombra y al hacerlo otorga existencia plena a lo nombrado. Somos nombrados mediante el lenguaje, entendido aquí desde la perspectiva de M. Bajtín, es decir, "como un devenir permanente y como producto de la interacción social de los hablantes" (Bubnova, 1996: 36) que, al inscribirse en el "gran tiempo", adquiere nuevos sentidos (Bajtín, 1995: 346-353), y mediante el lenguaje nombramos al mundo en el cual existimos y nos identificamos como iguales o diferentes, precisamente, por el nombre. La palabra que nos nombra, dice Irena Majchrzak, "nos acompaña desde el nacimiento y más allá de la muerte. Es la palabra inicial de la vida” (Majchrzak, 2007: 85). El nombre se convierte, así, en el vínculo entre el lenguaje y la vida:

Todo lo que se refiere a mi persona, comenzando por mi nombre, llega a mí por boca de otros (la madre), con su entonación, dentro de su tono emocional y volitivo. Al principio tomo conciencia de mí mismo a través de los otros: de ellos obtengo palabras, formas, tonalidad para la formación de una noción primordial acerca de mí mismo... como el cuerpo se forma inicialmente en el seno (cuerpo) materno, así la conciencia del ser humano despierta inmersa en la 
Dar el nombre es dar la palabra y con ella el lenguaje que nombra y con el que nombramos a aquellos que nos han nombrado. Desde esta perspectiva el nombre se erige como un territorio donde la presencia del otro o de los otros se manifiesta de una manera rotunda. El otro, entendido aquí como una entidad que nos compromete y nos exige responsabilidades porque los significados y sentidos de nuestros actos se definen, precisamente, por el carácter ético que implica la relación con el otro ${ }^{3}$. $\mathrm{Su}$ presencia es tan definitiva que, en palabras de Octavio Paz, posibilita nuestra existencia: "[...] soy otro cuando soy, los actos míos / son más míos si son también de todos / para que pueda ser he de ser otro / salir de mí, buscarme entre los otros / los otros que no son si yo no existo / los otros que me dan plena existencia [...]" (Paz, 1982: 79-80). Y que algunos autores, como Gilles Deleuze, consideran determinante a tal grado que, incluso, el nombre propio sólo adquiere su verdadera dimensión cuando se reconocen, precisamente, las huellas que el otro o los otros han dejado en nosotros:

\footnotetext{
Decir algo en nombre propio es muy curioso; porque no es en absoluto en el momento en que uno se toma por un yo, una persona o un sujeto, cuando se habla en su nombre. Al contrario, un individuo adquiere un verdadero nombre propio como consecuencia del más severo ejercicio de despersonalización, cuando se abre a las multiplicidades que le atraviesan de parte a parte, a las intensidades que le recorren (Deleuze, 2005: 13)
}

Esas multiplicidades e intensidades que atraviesan y recorren al sujeto se desprenden de la densidad discusiva que nos circunda por doquier, en la medida en que interactuamos en los ámbitos socioculturales donde nombramos y somos nombrados incesantemente.

b) El nombre como un samblaje

"Detrás del nombre hay lo que no se nombra" Jorge Luis Borges

Si un samblaje es aquel soporte que permite unir o juntar piezas ¿qué piezas aparecen unidas en nuestro nombre y en el nombre de los otros? ¿Cuántas y cuáles representaciones e imaginarios llevamos adheridas en él? ¿Qué de la época en que nacimos se filtró en nuestro nombre y en el nombre de los otros? ¿Cuántas y cuáles representaciones e imagina3.- M. Bajtín, Yo también soy (fragmentos sobre el otro), Trad. Tatiana Bubnova, México, Taurus, 2000, pp. $16-18$ 
rios heredaron nuestros padres al momento de nombrarnos? ¿Cuántas y cuáles representaciones e imaginarios heredamos a nuestros hijos al momento de nombrarlos? ¿Qué de la época en que nacieron se filtró en el nombre que ahora llevan? O, para decirlo con Jorge Luis Borges ${ }^{4}$, ¿qué hay detrás del nombre que no se nombra?

$\mathrm{Al}$ ser resultado de una práctica cultural que nos sitúa en los ámbitos de la socialización, el nombre forma parte de la dimensión simbólica de la cultura y constituye un samblaje de lo individual con lo social. Es la expresión de la singularidad en medio de lo diverso.

Para ilustrar lo anterior, es necesario considerar que las representaciones sociales "están ancladas en una cultura, con sus saberes populares, mitos, tradiciones y, por lo tanto, responden a las características particulares de cada tradición histórico cultural”. (Banchs, 2000: 63). Son construcciones simbólicas creadas y recreadas en los procesos de interacción social. Según Serge Moscovici, las representaciones sociales son: "[...] una modalidad particular del conocimiento, cuya función es la elaboración de los comportamientos y la comunicación entre los individuos [son] un corpus organizado de conocimientos y una de las actividades psíquicas gracias a las cuales los hombres hacen inteligible la realidad física y social, se integran a un grupo o en una relación cotidiana" (Moscovici, 1979: 17-18).

En palabras de Gilberto Giménez las representaciones sociales conforman una organización significante de la realidad y constituyen: "[...] 'una forma de conocimiento socialmente elaborado y compartido, que tiene una intencionalidad práctica y contribuye a la construcción de una realidad común a un conjunto social' [...]" (Giménez, 2005: 80-81). Según este mismo autor, la importancia de las representaciones sociales no sólo es de carácter teórico ya que, junto al habitus de Bourdieu, son parte de los paradigmas metodológicos que permiten el estudio de las formas interiorizadas de la cultura:

[...] es posible identificar un campo específico y relativamente homogéneo asignable a la cultura, si definimos a esta por referencia a los procesos simbólicos de la sociedad. Es lo que llamaremos, con Clifford Geertz y John B. Thompson, la 'concepción simbólica' o 'semiótica' de la cultura. La cultura tendría que concebirse entonces, al menos en primera instancia, como el conjunto de hechos simbólicos presentes en una sociedad. $\mathrm{O}$, más precisamente, como la organización social del sentido, como pautas de significados 'históricamente transmitidos y encarnados en formas simbólicas, en virtud de las cuales los individuos se comunican entre sí y comparten sus experiencias, concepciones y creencias'

(Giménez, 2005: 67-75)

4.- Nos referimos a uno de los versos del poema "Una brújula", del libro El otro, el mismo, de Jorge Luis Borges. Borges, Jorge Luis, Obras Completas, Buenos Aires, Emecé, 1989, vol. II, p. 253. 
El nombre constituye la inscripción simbólica primigenia que los seres humanos recibimos al nacer: "Sabemos que el nombre es la primera inscripción simbólica del ser humano y precede aún nuestro nacimiento" (Tesone, 2009: 195). Para subrayar su importancia conviene ahora definir lo que se entiende por simbólico y lo haremos a partir de lo que señala Gilberto Giménez:

[...] lo simbólico es el mundo de las representaciones sociales materializadas en formas sensibles, también llamadas 'formas simbólicas', y que pueden ser expresiones, artefactos, acciones, acontecimientos y alguna cualidad o relación. En efecto, todo puede servir como soporte simbólico de significados culturales: no sólo la cadena fónica o la escritura, sino también los modos de comportamiento, las prácticas sociales, los usos y costumbres, el vestido, la alimentación, la vivienda, los objetos y artefactos, la organización del espacio y del tiempo en ciclos festivos, etcétera. En consecuencia, lo simbólico recubre el vasto conjunto de los procesos sociales de significación y comunicación [...] (Giménez, 2005: 67-75)

Concebido como el primer rasgo distintivo con el que nos reciben en el seno de una familia, el nombre se erige como portador de "saberes, valores, creencias y prácticas [...] en contextos históricamente específicos y socialmente estructurados" (Giménez, 2005: 67-75). Y, para decirlo con Bourdieu, el nombre también forma parte del capital simbólico (Bourdieu, 1997:135) que recibimos al nacer y constituye el soporte mediante el cual tenemos acceso a la vida social:

\begin{abstract}
Así, el nombre propio es el soporte (sería tentador decir la sustancia) de lo que se llama el estado civil, es decir de este conjunto de propiedades (nacionalidad, sexo, edad, etc.) ligadas a una persona con las que la ley civil asocia unos efectos jurídicos y que instituyen, aparentando constatarlos, los actos de estado civil. Fruto del rito de institución inaugural que marca el acceso a la existencia social, constituye el objeto verdadero de todos los ritos de institución o de nominación sucesivos a través de los cuales se elabora la identidad social: esos actos (a menudo públicos y solemnes) de atribución, efectuados bajo el control y con la garantía del Estado, también son designaciones rígidas, es decir válidas para todos los mundos posibles, que desarrollan una verdadera descripción oficial de esta especie de esencia social, trascendente a las fluctuaciones históricas, que el orden social instituye a través del nombre propio; se asientan todos en efecto en el postulado de la constancia de lo nominal que presuponen todos los actos de nominación [...] (Bourdieu, 1997: 80)
\end{abstract}

Vida social que, entre muchos otros aspectos, se caracteriza porque en ella acontecen los procesos de significación entre los cuales se encuentran las representaciones que una colectividad hace de sí misma mediante lo que se conoce como imaginarios sociales:

[...] un conjunto real y complejo de imágenes mentales, independientes de los criterios científicos de verdad y producidas en una sociedad a partir de heren- 
cias, creaciones y transferencias relativamente conscientes; conjunto que funciona de diversas maneras en una época determinada y que se transforma en una multiplicidad de ritmos. Conjunto de imágenes mentales que se sirve de producciones estéticas, literarias o morales, pero también políticas, científicas y otras, como de diferentes formas de memoria colectiva y de prácticas sociales para sobrevivir y ser transmitido (Escobar Villegas, 2000: 113)

El imaginario se advierte en las representaciones que los sujetos construyen discursivamente y que portan su percepción de la realidad, su visión del mundo en el tiempo y el espacio en el que transcurre su existencia.

c) El nombre y la memoria de los otros

“iEn la miniatura de una sola palabra, caben tantas historias!"

Gastón Bachelard

Si el nombre es el elemento mediante el cual adquirimos presencia en el mundo y a través del cual participamos de esa "organización social de significados" (Giménez, 2007: 49) que es la cultura, en este apartado nos detendremos a identificar la memoria de los otros inscrita en él. Lo haremos a partir de ciertas historias seleccionadas e incorporadas al presente artículo como testimonios, es decir, como narraciones que dan cuenta de los complejos entramados entre memoria individual y memoria colecti$\mathrm{va}^{5}$.

Algunas de estas historias fueron tomadas de textos literarios o de ficción, otras aparecieron en la prensa como noticias del día y las demás corresponden a diversas voces que, en distintos momentos, contestaron a la interrogante: ¿qué hay detrás del nombre que no se nombra? En ellas encontramos declaraciones, opiniones, controversias y denuncias en torno a diversas prácticas, representaciones e imaginarios asociados al nombre: entre todas conforman esa memoria declarativa, expresada en el lenguaje, de la que habla Paul Ricoeur:

\footnotetext{
Pasamos de la memoria individual a la memoria colectiva, tránsito perfectamente legítimo, en la medida en que, gracias al lenguaje, las memorias individuales se superponen con la memoria colectiva. Decir que nos acordamos de algo, es declarar que hemos visto, escuchado, sabido o aprehendido algo, y esta memoria declarativa se expresa en el lenguaje de todos, insertándose así, al mismo tiempo, en la memoria colectiva [...] (Ricoeur, 2002: 27)
}

Veremos, así, cómo en el nombre se revelan huellas sociales, culturales e ideológicas que nos hablan de significados, de representaciones e imaginarios construidos en un tiempo y un espacio específicos. A ello se re-

5.- Jelin, Elizabeth, Los trabajos de la memoria, Siglo XXI, Madrid, 2002, pp. 17-18. 
fiere Walter Benjamin cuando afirma irónicamente: "También los rusos 'gustan' dar a sus hijos nombres 'deshumanizados': los llaman 'Octubre' según el mes de la revolución, o 'Pjatiletka' según el plan quinquenal, o 'Awischim' según una sociedad de líneas aéreas”. (Benjamin, 1989: 170). Porque el nombre hace surgir en el lenguaje la memoria de quienes nos nombraron, incluyendo su tono emocional y volitivo, pero también las condiciones materiales y simbólicas en el que fue concebido.

A continuación presentamos ese conjunto de testimonios con los cuales queremos ilustrar que más allá del significado lingüístico y etimológico que el nombre pueda tener, lo que resuena en él son las creencias, las valoraciones de un otro, formado por aquellos que participaron en el ritual de dar el nombre: la madre, el padre, los abuelos, los tíos, los padrinos, etcétera, y veremos cómo el nombre se inscribe en el horizonte de una historia simbólica tanto familiar como social que, en ocasiones, se confronta con las valoraciones sociales y culturales propias de un tiempo y un espacio específicos, convirtiéndose en soporte de reivindicaciones identitarias o de denuncia ante la discriminación, la violencia o el olvido. Entre todos conforman un concierto de voces en las que resuenan nombres singulares y, con ellos, un raudal de valoraciones, representaciones e imaginarios que tejen la trama entre palabra, memoria, visión del mundo e identidad.

\section{Testimonios}

a) Testimonios de textos literarios o de ficción

\section{Testimonio 1}

"Señor

Recibe a esta muchacha conocida en toda la tierra con el nombre de Marilyn Monroe aunque ése no era su verdadero nombre (pero Tú conoces su verdadero nombre, el de la huerfanita violada a los 9 años

y la empleadita de tienda que a los 16 se había querido matar)

y que ahora se presenta ante Ti sin ningún maquillaje sin su Agente de Prensa

sin fotógrafos y sin firmar autógrafos

sola como un astronauta frente a la noche espacial”"

\section{Testimonio 2}

6.- Ernesto Cardenal, Nueva antología, Siglo XXI editores, $11^{\text {a }}$. edición, México, 2002, p. 88. 
“'Pues póngale nomás Juan' como si con dar su nombre temieran molestar, ocupar un sitio en el espacio y en el tiempo que no les corresponde, 'nomás Juan'. Al principio, cuando les preguntaba: ‘¿Cómo se llama usted?' venía el sobresalto: ‘¿Quién?' 'Usted’ ‘¿Yo?' 'Sí, usted’. 'Pues póngale nomás Juan, o lo que quiera, Ciro me llamo pero puedo responder a otro nombre, al que usted mande, cualquiera es bueno’. Me di cuenta que su ‘¿quién?' equivale a 'nadie'. ‘¿Quien anda allí?' 'Nadie' contesta la multitud. Todo regresa al silencio y todos lo nutrimos porque los que responden preguntando: ‘¿Quién?' nunca han tenido derecho a nada, ni siquiera a que se les designe con un nombre, toda su vida ha sido un largo y continuo soportar que se les haga a un lado $[. . .]^{\prime \prime}$

\section{Testimonio 3}

"- Pues resulta que una amiga andaba jode y jode con que fuéramos compadres, y que yo bautizara a su chavita. Y le dije: 'Bueno, órale'. Y luego hice cita con un cura, y pasé por la niñita. Y me pregunta el vato: ‘¿Y cómo se va a llamar?'. Saqué el papelito que me dio la mamá, y le digo: 'Danna Jocelyn'. El vato se sacó de onda: ‘¿Cómo que Danna Jocelyn? ¿Qué nombre es esto? Ustedes no tienen respeto alguno por su país, no aman sus tradiciones, me niego a ponerle a la niña ese nombrecito'. Que me encabrono y le explico: 'Mire, ese nombre va porque a su mamá se le pega su pinche gana, y quién carajos nos pidió permiso para ponernos Pedro y Roberto y Hernán. No, curita (así le digo siempre), aliviánese y no se meta en bisnes ajenos'. Y él todavía me dice: 'No, hijo, el Señor no puede aprobar que le faltes al respeto a su tradición'. Y ya muy enchilado, le respondo: 'En primer lugar no soy su hijo, aunque usted debe tener varios, y en segundo, y con todo respeto, fíjese en su aspecto. ¿Usted cree que sus antepasados indígenas no hubiesen protestado si saben que a usted le pusieron Baltasar en lugar de Axayácatl? Aliviánese y bautice a esta niña como Danna Jocelyn'. Y así se hizo"8

\section{Testimonio 4}

“- ¿Y tú por qué te llamas así, abuela?

Luego, el peine recorría su cabeza de punta a punta para trazar una línea recta que la separaba en dos mitades iguales, y Anita, absorta en la destreza de sus dedos, que dividían y subdividían los mechones con una precisión casi mecánica, tardaba algunos segundos en con-

7.- Elena Poniatowska, Fuerte es el silencio, Ediciones Era, 17a. reimpresión, México, 2006, p. 11.

8.- Carlos Monsiváis, "Para un cuadro de costumbres. De cultura y vida cotidiana en los ochentas", en Cuadernos Políticos, número 57, Editorial Era, mayo-agosto de 1989, México, p. 99 
testar.

- Pues porque así me pusieron.

- Pero te pondrían Ana ¿no?

- Sí, claro. Mi padre quería llamarme Placer, pero a mi madre no le gustaba. Decía que no era un nombre de mujer decente, trabajadora... - la niña no podía mirarla, pero sabía que su abuela estaba sonriendo, que siempre sonreía al contar esa especie de chiste al que ella nunca le había visto la gracia-. Y como era la pequeña de mi casa, y soy tan bajita, y tenía sólo quince años cuando nos marchamos. No sé, siempre me han llamado Anita.

Terminaba con una trenza, empezaba con la segunda, y las dos le salían iguales de bien, de la misma longitud, el mismo grosor y ni un solo pelo suelto, firmes pero flexibles, apretadas y simétricas como espigas de trigo.

- ¿Y tú? -le preguntaba luego-. ¿Tú sabes por qué te llamas Raquel? - Claro que sí - tomaba aire y contestaba de carretilla, como cuando la sacaban a la pizarra en el colegio y se sabía de memoria la lección-. A la abuela Rafaela no le gustaba su nombre, pero quería que mamá supiera decir bien la erre y por eso buscó uno más bonito que empezara igual que el suyo, y Raquel fue el que más le gustó, y a ella y a papá también les gusta, y por eso me lo pusieron aunque dicen que lo de la erre es una tontería" 9

\section{Testimonio 5}

“- Yo le prometí a la Virgen que si consigo dinero y me caso el año entrante, mi primer hijo se llamará Guadalupe, sea hembra o varón. - Qué bueno que esa promesa no se la hiciste a la Virgen de Fátima” 10

\section{Testimonio 6}

“- Señora, al dar sus generales dijo usted llamarse Rosa Smith Saltarini.

- No, yo me llamo Tina Modotti.

- ¿Ah, sí? ¿Por qué dio usted otro nombre? [...]

Silencio en el aire. La mecanógrafa hace girar el rodillo de la Underwood. Tarda en sacar el papel carbón e insertarlo entre las hojas. Rosa Smith Saltarini, de veintidós años, viuda, oriunda de San Francisco, California, profesora de inglés y domiciliada en la casa número veintiuno de la calle de Lucerna. ¿Por qué habré pensado

9.- Almudena Grandes, El corazón helado, TusQuets, Madrid, 2007, pp. 30-31.

10.- Carlos Monsiváis, Los rituales del caos, Ediciones Era, México, 1995, pp. 40-41. 
en Saltarini?, se pregunta sonriente en su fatiga. Saltarini es otro de mis apellidos, tonta que soy, nunca he sabido mentir. El Saltarini le hace sentir ternura por sí misma y por ese abuelo y aquel bisabuelo, al recordar que saltaban como chivos en los campos de Udine, ganándose así el nombre de saltarines, de chivitos brincones. Eran tan pobres que no habían alcanzado apellido, sólo un sobrenombre: 'Allí vienen los saltarines'. Tina gozó una súbita visión de Istria, de Friuli, de su abuelo-niño saltando los arroyos, de ella, de Mercedes, de Gioconda, de Yole, de Benvenuto, a brinca y brinca, sus piernas en el aire, y la mamma gritándoles que ya, que se metieran porque Beppo quería cenar, y ellos -porque sólo saltan los que son felicesentraban a puro salto en la casa a recogerse al final del día en torno a la polenta. Hacía mucho que Tina no pensaba en su infancia, en Udine; todo lo había absorbido Julio, era como si de pronto Julio la arrojara al mundo, desnuda, recién nacida. De llamarse Rosa Smith no sería ella, Tina, la que ahora bajo esta luz descarnada respondiera preguntas, ni sería Julio quien la aguardara metido en un cajón, porque Julio Antonio nunca amó a Rosa Smith.

- Señora, tiene usted que ser muy precisa. Tina ¿es su verdadero nombre? ¿Tina, así como la del baño?

- Bueno, es Assunta pero me dicen Tina. Tina recuerda que su madre la llama Tinísima y de pronto mira cómo el rostro de su madre se ensancha en el juzgado [...]

- ¿Es ese su único nombre?

- Assunta, Adelaida, Luigia...

- Eso no consta en el expediente; hay que añadir esa letanía que siempre se ponen los extranjeros. ¿Y el apellido?

- Modotti.

- ¿Cómo se escribe? A ver, escríbalo usted para poder copiarlo y de una vez el materno.

- Modotti.

- A ver, póngalo letra por letra [...]"11

Testimonio 7

"[...] La camioneta amarilla amaneció en distintas esquinas del barrio hasta que Zoraida, mi hermana de en medio, decidió hacer el primer negocio de su vida: rentó la mitad de nuestro refrigerador. -iLes salió lo árabe! -gritó Maximiano, quien sabía perfectamente que lo único árabe en la casa eran los nombres con qué mi padre bautizó a sus hijas (mi madre, por supuesto, sospecha que Amira,

11.- Elena Poniatowska, Tinísima, Ediciones Era, México, 1992, pp. 49-50. 
Zoraida y Sureya son los diamantinos seudónimos de sus vedetes favoritas)"12

\section{Testimonio 8}

"Soy Maya Vidal, diecinueve años, sexo femenino, soltera sin un enamorado, por falta de oportunidades y no por quisquillosa, nacida en Berkeley, California, pasaporte estadounidense, temporalmente refugiada en una isla del sur del mundo. Me pusieron Maya porque a mi Nini le atrae la India y a mis padres no se les ocurrió otro nombre, aunque tuvieron nueve meses para pensarlo. En hindi, maya significa 'hechizo, ilusión, sueño'. Nada que ver con mi carácter. Atila me calzaría mejor, porque donde pongo el pie no sale más pasto"13

\section{Testimonio 9}

"Como la primera mujer de Adán, Lilith, en honor de quien llevaba el nombre, ella había hecho de su independencia absoluta casi una religión. Algo más que debía a su madre: para bien y para mal, con el nombre, con la leche, con el ejemplo diario, incluso con el abandono, le había transmitido la rebeldía, la independencia. Y ese nombre extraño era otra de las cosas que, por unirla a su madre, quiso hacer desaparecer: a los dieciocho se había convertido en Lilia y así la llamaron todos desde entonces" ${ }^{14}$

\section{Testimonio 10}

"Uno tiene nombre. Se apellida. Uno es mucho eso: su K, su A, su W. También la $\mathrm{G}$ y la $\mathrm{R}$ son. El hijo, la madre, el abuelo, la abuela. Uno es un poco su nombre, otro tanto sus apellidos y en alguna porción, el mote callejero. ¿Cómo nacer sin apellidarse? ¿Caminar sin identidad? ¿Cómo cavar tumbas con lápidas que tan sólo lleven nombres? Los apelativos se repiten y repiten, pero las homonimias con dos apellidos son poco frecuentes. Uno es uno. Uno es también tiempo. Se nace una vez. En un momento que es un día, de un mes, de un año $[\ldots]]^{\prime 15}$

\section{Testimonio 11}

12.- Juan Villoro, El disparo de argón, en el sitio: http://portales.mx.cervantesvirtual.com/servlet/SirveObras/p328/12708302325620495654435/p0000001.htm\#I_0_ (consultado el 13 de septiembre de 2012).

13.- Isabel Allende, El cuaderno de Maya, Plaza y Janés, España, 2011, p. 15.

14.- Celia del Palacio, Mujeres de la tormenta, Summa de Letras, México, 2012, p. 38.

15.- Arnoldo Kraus, "Holocausto: memoria y tautología", en La Jornada Semanal, domingo 16 de febrero del 2003, núm. 415. 
"Se nacía con un nombre que luego se cambiaba al encontrar el verdadero: fue lo ocurrido con ese hidalgo que toda su vida se llamó Alonso Quijano y, en su madurez, don Quijote de La Mancha. Los latinos agregaban un sobrenombre para describir a la persona; así, Marco, de la familia Tulia, fue conocido como Cicerón ("garbancito") por una verruga que el orador tenía en la nariz. En otras culturas, el verdadero nombre se ocultaba por cuestiones mágicas y se ofrecía al mundo uno distinto (falso, social, metafórico): en Éxodo 3, 14, Yahvé le dijo a Moisés, cuando éste interrogó a la zarza ardiente y le preguntó su nombre: "Soy El que Soy", es decir, eludió revelarse y sólo mostró una de sus cualidades. ¿̇Qué significa llamarse Milena en la sociedad contemporánea, otorgadora de nombres antes de que el recién nacido busque el suyo, desarrolle una personalidad o manifieste sus atributos? Ese nombre eslavo ha sido relacionado con "la pacífica", "la eterna" y, cuando se vincula con el nombre de Magdalena, con "la que vive sola en el torreón", "la magnífica". Además de esas hipótesis nominalistas, pero incluyéndolas a todas, Milena es "la llena de gracia", derivación de Mila, "la querible", "la amada"; llamarse así es, también, alimentarse de lo que otras Milenas han construido en el pasado"16

Testimonio 12

“- ¿Y de nombre? ¿Qué nombre le ponemos?

- Pues yo había pensado ponerle...

- ¿Purificación?

- ¿Purificación? ¿Pura? ¿Pura?

- ¿Qué habías pensado tú?

- Herminia

- iVamos, hombre, no digas tonterías!

- iHombre, como mi madre!

- Pues me gusta mucho más Purificación...

- iNo!

- iPero madre, yo pensé que te haría ilusión que la niña se llamara igual que tú!

- iQue no mujer, con una Herminia en la familia ya es bastante!

- iPor eso decía yo que se podía llamar Purificación!

- ¿Pura? iPobre criatura!

- ¿Por qué no si Purificación es muy bonito madre?

- Luego va a sufrir como yo, ya verás...

16.- Enrique López Aguilar, "Milena”, en La Jornada Semanal, Domingo 21 de enero de 2007, núm. 620. 
- Mira, pues nada, entonces la podríamos llamar Carmen, que a mí me gusta mucho, no sé por qué...

- iNo, la podríamos llamar Maika!

- ¿Cómo?

- ¿Maika? ¿eso es nombre para una cristiana?

- iEso es nombre de rusa!

- Es el nombre de la chica que te gusta, ¿a que si?

- iNo me gusta!

- Bueno ¿̇y Teresa, como se llamaba mi cuñada que en paz descanse?

- ¡A mí me gusta Teresa! iTeresa!

- Teresa, es bonito, iMaría Teresa! iMe gusta María Teresa!"17

\section{Testimonio 13}

“- Oye, ¿por qué te llamas Sibila?

- Me pusieron así ¿por qué?

- No sé, es raro...

- Y tú, ¿cómo te llamas?

- Félix, ¿̇por?

- ¿Félix? iComo nombre de gato!"18

Testimonio 14

"- Diega no existe, Diega es un invento, no es como Juan que le ponen Juana, Luis que le ponen Luisa. No existe Diega, no existe.

- Hay muchos nombres raros... yo quiero ponerle...

- No me lo van a aceptar...

- ¿Y si le ponemos Diego?

- iPero cómo le vas a poner Diego si es una nena!

- Métale Dalma

- ¿Dalma?

Este muchacho Benítez esperaba un varón y el segundo también fue nena... finalmente llegó el varón: Diego Armando"19

b) Testimonios de textos periodísticos

\section{Testimonio 1}

17.- Fragmento del capítulo 40, segunda temporada de la serie Cuéntame cómo pasó, en el sitio: http://www. rtve.es/alacarta/videos/cuentame-como-paso/cuentame-como-paso-t2-capitulo-40/882955/ (Consultado el 30 de noviembre de 2012).

18.- Fragmento del capítulo 8, quinta temporada de la serie Los ochenta, en el sitio: http://www.youtube.com/ watch? $=8 x$ PmlFHYfRQ (Consultado el 19 de noviembre de 2012)

19.- Fragmento de la película "El camino de San Diego", de Carlos Sorin, en el sitio: www.elcaminodesandiego. com/ (Consultado el 10 de julio de 2012). 
"Tabasco no sólo tiene como referente a sus políticos cargados con la pasión del trópico, a su poeta Carlos Pellicer, al plátano y sus platillos típicos, como el pejelagarto y el tamal de chipilín. Hay otro aspecto que atrae la atención de propios y extraños: los nombres 'raros, feos y hasta simpáticos' de algunos de sus pobladores. En esta entidad, por ejemplo, hay personas que llevan el nombre de Hipotenusa, Masiosare, Primo, Oliver Onice, Deltránsito, Belú, Sero, Florizel, Tabasco, Grijalva, Villahermosa, Lenin, Hitler, Trosky, Volter, Linier, Aristóteles, Diógenes, Platón, Laureano, Cinico, Celito, Decoroso, José Superman, Casiano, Egonomia, Sopelo, Cerbula, Amnesis, Eutilo y Eleudomina, por mencionar sólo algunos" ${ }^{20}$

Testimonio 2

"[...] En el Registro Civil de la entidad se han inscrito nombres que, por su composición, se escriben y pronuncian de manera insólita. Por ejemplo: Frígida, Tecla, Tasita, Potasia y Santita María. En el bando masculino, la situación no es muy diferente. León Papa [...] Perico, Bradamante, Cariño Leónides y se celebran a cantantes como Chayanne y Ricky Martin. Sin embargo, así como estas personas fueron asentadas en el Registro Civil por sus padres, al paso de los años decidieron cambiar parcial o totalmente sus nombres. La dificultad que entrañaba para ellos su pronunciación e incluso las burlas de que eran objeto representó una pesada carga y terminaron por aligerarla o, de plano, desterrarla. En 2004, según el director del Registro Civil, Rafael Basurto Ojeda, un total de mil 482 yucatecos hicieron trámites para modificar parcialmente su nombre o adquirir una nueva identidad. Un total de 894 mujeres, siendo aparentemente las más perjudicadas, cumplieron los requisitos para transformar sus nombres, mientras que 588 hombres visitaron el Registro Civil para hacer lo mismo [...] El Registro Civil incluye a una amplia gama de nombres sui generis. Por ejemplo están Anillo Lancia, Atos de Jesús [...] Farkhondepour, Bradley Jadiel, Bradly Smark, Cancionilo Toribio, Canimicer, Lecter [...] Castillo, Cocalet, Coco, Diosdócoro Trimagesto, Epitacio, Este, Gato, Hulkín [...] También figuran Mano Audomaro, Melchicedec, Mikey Monte, Ojorkaeff, Pepito [...] Perico, Piel de Ángel, Torcuato Tristeo, Uno Elías, Vacarión, Vander Lecaw y Profeta Malaquías. En el bando femenino no son menos los nombres extravagantes en el Registro Civil. Aserejé, Azul Zafiro, Cenicienta, Fea, Feayme, Golondrina de

20.- La Jornada 2 de junio de 2012, en el sitio: http://www.jornada.unam.mx/2006/02/06/index.php?section=estados\&article=038 (Consultado el 13 de julio de 2012). 
Madinina, Mafalda [...] Mamá Antonia, Melrose Olinca, Memoria María, Okira, Soyukki, Olimpiada, Pala y Poderosa Angélica [...] Salud del Carmen, Santita María, Sayuridayanara Guadalupe, Seisi, Torbellina del Socorro, Vanda Perla, Virgencita y hasta Virgen María $[\ldots]{ }^{21}$

\section{Testimonio 3}

"Hace un año y cinco meses, César Cruz Uribe y su esposa, Marisela Rivas López, una pareja ñañú, acudió a registrar a su hija con el nombre de Doni Zänä Cruz Rivas, que en su lengua significa Flor de Luna, pero ni en Tepeji ni en Tula de Allende ni en el registro estatal fue aceptada tal opción con el argumento de que 'ese nombre no lo registra el sistema de cómputo'. César y Marisela iniciaron una lucha en defensa de su cultura, sus tradiciones, su lengua y, sobre todo, su origen étnico, en contra de autoridades civiles que, a diferencia de la Iglesia católica, han ridiculizado su demanda, la han calificado de 'capricho' y le han sugerido ponerle a la niña un nombre 'menos complicado'. José Antonio Bulos Salomón, director del Registro del Estado Familiar en Hidalgo, funcionario de ascendencia libanesa, ha calificado la lucha de César y Marisela como 'un capricho que traerá consecuencias negativas' para la pequeña. El funcionario trata de matizar: la oposición de las autoridades 'no es por negligencia ni porque tengamos algo en contra de preservar las tradiciones o costumbres de nuestros pueblos, porque todos somos hidalguenses y a todos nos enorgullece escuchar un nombre ñañú, pero lamentablemente los sistemas (de cómputo) no lo contemplaron. Esto data del año 2000 o finales de 1999, cuando se implantó este sistema'. Pero Yolanda Hernández, maestra del Centro Estatal de Lenguas y Culturas Indígenas de la Secretaría de Educación Pública de Hidalgo, reta a las autoridades a probar que no es posible escribir en cualquier computadora el nombre como lo piden los padres. La Jornada pudo escribir Doni Zänä con tan sólo subrayar la letra o y poner diéresis a las aes. Para acabar con 'la guerra mediática' que ha iniciado la familia Cruz Rivas, le han hecho propuestas, pero ninguna cumple la petición de que la menor lleve el nombre que los padres quieren. La pareja ha advertido que no se dejará intimidar. La semana pasada el secretario de Gobierno, Francisco Olvera Ruiz, mandó llamar al padre para sugerirle, enojado, que busque otra alternativa y le ponga otro nombre a su hija. 'Están

21.- La Jornada 18 de enero de 2005, en el sitio: http://www.jornada.unam.mx/2005/01/18/a09n2esp.php (consultado el13 de julio de 2012). 
atropellando mis derechos -señala el padre-. Si la computadora no registra el nombre, como argumentan, pues lo hacemos en un documento manuscrito, pero me imagino que han de pensar: si registramos ese nombre, se nos va a venir la pinche indiada'. Jesús Silva Cadena, delegado de la Comisión Nacional para el Desarrollo de los Pueblos Indígenas (CDI), reconoció la necesidad de hacer reformas a la ley que garanticen el respeto a las lenguas indígenas y ofreció su apoyo a la familia en esta 'cruzada en favor de la raza ñañú', y no sólo por la defensa de un nombre. El caso llegó a la delegación de la Secretaría de Relaciones Exteriores en Hidalgo, cuyo titular, Ricardo Santana Velásquez, en un oficio fechado el 11 de abril y dirigido al Registro del Estado Familiar, aclaró que con el nombre de Doni Zänä 'no será posible expedir el pasaporte con las especificaciones del guión bajo y las diéresis; sin embargo, el nombre de Doni Zana (sin esos signos) sí podría expedirse'. El padre de familia informó que su caso se abordará durante el Encuentro Latinoamericano de Registro Civil e Identidad, que se realizará en la ciudad de México en junio. En su humilde vivienda en la comunidad de San Ildefonso, César y Marisela, acompañados de sus hijas, Joselin, de 12 años; Perla Samanta, de 10; Yohoki, de siete, y Noelia Antonia, de cinco, sostienen que 'no se trata de un capricho', sino de una lucha, primero, por el derecho de los padres a preservar su lengua, su tradición y su raza, y porque la niña tiene derecho a un nombre. Ponerlo de otro modo le daría un significado distinto, señala el padre de la menor a Raúl Baños, visitador de la Comisión de Derechos Humanos del Estado de Hidalgo (CDHEH), en un escrito fechado el 7 de marzo: 'Si el nombre de mi hija quedara sin el subrayado y sin las diéresis, en nuestra lengua tendría un significado diferente, como Doni, que es piedra, y Zana, ten, muerde'. Es decir, Doni Zänä significa Flor de Luna, pero sin los signos de acentuación significaría algo así como piedra que muerde. 'Pensamos en el primer nombre porque nos dedicamos a la venta de flores en la temporada del Día de Muertos y nuestra hija nació el primero de noviembre. De ahí la intención de ponerle el nombre que en español significa Flor de Luna', argumenta César Cruz. Recuerda que cuando fue a registrar a la tercera de sus cinco hijas, Yohoki, en el Registro del Estado Familiar le reclamaron que está prohibido ponerles a los niños 'nombres extranjeros o de artistas. Yo les respondí que ese es un nombre ñañú, no japonés ni chino, y significa en nuestra lengua renacer, renovar, rehacer o hacer entre dos. ¿Dónde está el extranjerismo? Su ignorancia los lleva a la intolerancia y al racismo' [...] Anticipa 
que le quedan tres años y medio antes de que su hija requiera documentos para ingresar a la primera etapa de su educación básica. 'Tengo tiempo para mantener mi lucha, la de mi familia y la de mi raza', finaliza" 22

\section{Testimonio 4}

"Leticia Hidalgo Rea llega a las siete de la tarde. Extiende cuidadosamente un tendedero para sostener cada uno de los pañuelos con horquillas. Abre su caja de costura y saca aros, hilaza verde y aguja. De pie, acaricia la tela donde está escrito Roy, el nombre de su hijo desaparecido hace 20 meses. Mete y saca la aguja con punto horizontal; en cada puntada hay compasión, ternura, catarsis, llanto, esperanza, paz... A su lado, se van sentando en el suelo de la calle peatonal de Hidalgo, en el centro de Monterrey, otras madres de desaparecidos; también hombres y mujeres que tienen familiares asesinados durante la guerra. Todos bordan: el color rojo-sangre es para imprimir los nombres y apellidos de los muertos; el verde-esperanza para los desaparecidos. La mayoría son mujeres. Son bordadoras por la paz. Han vencido el miedo y han salido a contar su historia. Cada pañuelo es una vida: Mi niño, te coloco en las manos de Dios. Te esperamos pronto, muy pronto. Roy, estudiante de la Universidad Autónoma de Nuevo León (UANL), fue secuestrado el 11 de enero de 2011: hijo mío, te podrán apartar de mi lado, pero nunca de mi corazón. Gino Alberto Campos Ávila, desaparecido el 8 de junio de 2011; Jaime Espinosa, asesinado el 8 de junio de 2011 al volver a su casa de trabajar. Las bordadoras se reúnen todos los domingos en la Plaza Zaragoza, pero hoy es 30 de agosto, Día Internacional del Desaparecido, y han colocado mantas especiales: Desaparecidos. ¿Donde están? Justicia. Poco a poco van poniendo los zapatos de los ausentes y entre bastidores bordan contra la guerra que no termina. Bordar es un acto de amor, una forma de integrar a la vida de uno el discurso de las víctimas, de la violencia y del dolor; una forma de resistir propia del lenguaje. Nos une como comunidad, y cada día hay más pañuelos, cientos, dice mientras borda la activista y escritora Cordelia Rizzo Reyes, comprometida con las víctimas de la guerra [...] Nadie sabía bordar o nadie se acordaba. Poco a poco fueron aprendiendo, rescatando el tradicional punto de cruz, la puntada atrás y rococó; la margarita y cadenilla; la japonesa y la rosa en base estrella. Con sus manos, las bordadoras las-

22.- La Jornada del 5 de mayo de 2007, en el sitio: http://www.jornada.unam.mx/2007/05/10/index. php?section=estados\&article $=035$ (Consultado el 13 de julio de 2012). 
timadas por la tragedia de la guerra fueron creando una atmósfera de relajación, aflojando los nudos de sus penas, soltando el dolor, liberando la angustia, la impotencia [...] Las bordadoras, una iniciativa del Colectivo Fuentes Rojas, han formado grupos en varios estados de la República y bordan no sólo los nombres de sus hijos, sino los de otras personas que nunca conocieron. Pretenden llenar la plancha del Zócalo con sus pañuelos para despedir a Felipe Calderón en el final de su sexenio y recordarle a cada una de las víctimas de su guerra: Que mire Calderón lo que nos hizo. El reto era bordar 60 mil, ahora sabemos que son miles más y vamos a bordar un pañuelo por cada uno. Queremos darles rostro, humanizar la tragedia. No son cifras ni todos eran delincuentes, tienen nombres, ilusiones, sueños, proyectos, familia, dice Blanca Silvia Navarro Escobedo, mientras borda el nombre de varias víctimas asesinadas en Guanajuato [...]"23

\section{Testimonio 5}

"Diversas organizaciones que aglutinan a familiares de desaparecidos y víctimas de la violencia realizarán protestas en todo el país y en el extranjero, a partir del próximo domingo 25 y durante toda la semana, para "despedir" a Felipe Calderón. Llevarán consigo regalos simbólicos, como bordados y veladoras, y harán un recuento de los daños que dejó la guerra contra el crimen organizado que impulsó el panista desde que inició su gobierno [...] El sábado 1 de diciembre, último día del mandato de Felipe Calderón, el Movimiento de Colectivos de Bordado por la Paz en México montará exposiciones en diversas ciudades del país y del extranjero para mostrar los cientos de pañuelos bordados con los nombres de personas asesinadas, desaparecidas y amenazadas durante su mandato. Señalaron que esos trozos de tela bordados por las familias dolientes son "el verdadero memorial a las víctimas de la guerra contra el crimen organizado", y el símbolo con el que quieren despedir el sexenio. 'Estos son un símbolo -así como un medio concreto de conservación de la memoria- de la violencia ejercida desde el mandato del presidente Felipe Calderón, quien deja al país sumido en una guerra arbitraria, siniestra y con serias fallas de estrategia $-\mathrm{y}$ operación- contra el narcotráfico. Su consecuencia más dolorosa ha sido la reiterada desprotección a las víctimas de este combate', indicó el movimiento en un comunicado" 24

23.- La Jornada 2 de septiembre de 2012, en el sitio: http://www.jornada.unam.mx/2012/09/02/politica/017n1pol (Consultado el 2 de septiembre de 2012).

24.- La Jornada del 5 de mayo de 2007, en el sitio: http://www.jornada.unam.mx/2007/05/10/index.php?sec- 
c) Testimonios de diversas voces

Testimonio 1

“- Mamá, los amigos de Santiago tienen nombres chistosos, uno se llama Sony y el otro Livais" ${ }^{25}$

Testimonio 2

"- Mi hija se llama Úrsula, por Gabriel García Márquez"

"- Mi hijo se llama Gabriel, por Gabriel García Márquez"

"- Mi hermano se llama Aurelio, por Gabriel García Márquez"

"- Mi sobrina se llama Amaranta, por Gabriel García Márquez"

“- Mi tío se llama José Arcadio, por Gabriel García Márquez” 26

Testimonio 3

"Mi carpintero, Silvestre, tuvo siete hijos, y él, antes de tener todos estos hijos, tuvo un amigo, que era marinero italiano, se llamaba Gino, 'gi' en italiano suena 'lli', se pronuncia 'Llino'. Y el marinero estuvo una temporada viviendo en Xalapa, eran compañeros y buenos amigos. Al final, el marinero decidió regresar a su patria. Entonces se despidió del carpintero y él, para conservar su recuerdo le dijo al amigo 'le voy a poner tu nombre a uno de mis hijos'. Le pidió que le escribiera su nombre en un papel, y así lo hizo, el marinero le escribió su nombre: Gino, con 'g'. Años después empezó a tener sus hijos y cuando nació el tercero decidió ponerle el nombre del amigo, porque se encontró el papelito con el nombre escrito: 'Gino', así lo registraron pero a Silvestre se le había olvidado la pronunciación del nombre y pasó a llamarse 'Jino'. En la escuela sus compañeros le decían 'jinicuil' y, ya de grande, optó por usar su segundo nombre: Alejandro, para evitar esas confusiones fonéticas” ${ }^{27}$

\section{Testimonio 4}

"Raquel, del Antiguo Testamento: Hermana menor de Lía, esposa (favorita) de Jacob, madre (con mucho trabajo) de José y Benjamín. Aparentemente fue una mujer triste, llena de constantes sufrimientos.

Raquel, mi abuela: Hermana menor de Luisa, esposa de Rogelio, madre de tres hijos: Rogelio, Carlos y Raquel. Abnegada, sumisa,

tion=estados\&article=035 (Consultado el 13 de julio de 2012).

25.- Colaboración de Pedro Rodrigo González García.

26.- Varias voces en comunicación personal.

27.- Colaboración de Leticia Tarragó. 
era necia aunque en realidad nunca se quejaba de nada; tuvo una vida difícil con su marido e hijos y, quizá por ello, pasó sus últimos años en silencio, con un eterno semblante de tristeza.

María Raquel, mi madre: Hermana menor de Rogelio y Carlos, esposa de José Antonio, madre (con mucho trabajo) de dos hijas: Sandra y Raquel. De carácter fuerte, de haber sido varón su papá la iba a llamar Rafael y, al ser mujer, le fue impuesto el nombre de su madre. Tenía el físico y el carácter de su padre (imponente, enojona, estricta), lo cual la hizo chocar mucho con su madre, aún en los últimos años de ésta. Como por arte de magia, todo lo que alguna vez criticó de Raquel, María Raquel lo ha hecho suyo, y se ha vuelto sumisa, callada, abnegada por decisión y, de pronto, con cierto dejo de tristeza en su rostro.

Raquel, yo: Hermana menor de Sandra, soltera y sin hijos. Mi papá me eligió el nombre en reconocimiento del trabajo que fue para mi madre embarazarse de nosotras, y en realidad nunca tuvo otra opción más que este nombre. Por alguna razón no fue la primogénita quien tuvo ese honor. Heredé el físico de mi madre y ese carácter enojón que solía caracterizar a María Raquel en sus buenos años. ¿Por qué llamarme Raquel si las Raqueles de mi familia (y desde la Biblia) tienen un halo de tristeza, dolor y sufrimiento en torno al tema de los hijos? ¿Será ese mi destino trazado no sólo por la vida, sino también por el hecho de llamarme como me llamo? ¿Sería capaz de tener una hija y llamarla así para seguir repitiendo este patrón en el que, posiblemente, yo también caiga con el paso de los años?"28

\section{Testimonio 5}

"Pudo ser el año 1992. Cursaba la secundaria y estaba en casa de mi amiga más querida, junto con mi familia. Nuestros padres alrededor de la mesa y nosotras algo alejadas, en la sala, hablando de nuestras cosas. Llegó un momento en que el tema de la plática de sobremesa llamó nuestra atención. Hablaban de nombres poco comunes, raros: 'fualnita me contó que alguien se llamaba...', o 'leí una nota de que en tal país a un niño le pusieron...' De repente, la anfitriona dijo algo así como: 'este nombre sí me consta porque es del hijo de una amiga querida: el niño se llama Jemarché. Los que no conocíamos la historia guardamos cinco segundos de silencio antes de soltar una tremenda carcajada. '¿Cómo? ¿Jema... qué?', preguntamos. 'Jemarché... por Jesús, Marx y el Ché'. Después de

28.- Colaboración de Raquel Guerrero Viguri 
la explicación dejamos de reírnos y hasta el día de hoy no se me puede olvidar el nombre" 29

\section{Testimonio 6}

"Cuentan las abuelas nahuas, mis abuelas, que nuestro nombre es una segunda piel, en el está inmersa parte de nuestra esencia. Dentro de la cosmovisión de nuestra cultura el nombre que se nos asigna tiene fuerza y poder. Es por ello que cuando alguien se 'asusta' se le lleva con un curandero(a) a que le 'levante la sombra' y lo 'llame' para que su 'tonal' (esencia divina que alimenta al alma) regrese a su cuerpo, sin esta curación la persona en cuestión empieza a decaer de ánimo, se fatiga, no come ni duerme bien. El curandero(a) entonces le hace una limpia con hierbas medicinales, pide un poco de tierra del lugar y con un poco de aguardiente soplado empieza a llamar por su nombre a la persona 'asustada', así el 'tonal' escucha y regresa al cuerpo, dotándolo de vitalidad y energía. Las abuelas dicen que hay que saber escoger el nombre de un niño pues su nombre lo va a significar a él, le dará fuerza en el camino de su vida, incluso hay una costumbre donde se le elige un 'toca' o 'tocayo(a)' al pequeño, quien aparte de su nombre llevará el nombre de su 'toca', esta persona se elige de acuerdo a las cualidades y virtudes que tenga para que el niño las absorba mediante el nombre y sirva como ejemplo de vida para la criatura. En fin, nuestro nombre resume y sintetiza lo que fuimos, somos y seremos, está dotado de fuerza, fortaleza, poder, en él está inmersa parte de nuestra esencia, todo esto en una palabra o varias, si tenemos más de uno como es mi caso: me llamo Beu Ribe Yantlanesi y significa Luna que espera un nuevo amanecer. He aprendido a llevar este nombre y a transformarme con él, de pequeña me apenaba un poco porque no es un nombre muy común y tenía que lidiar con las eternas preguntas que la gente hace cuando lo digo por primera vez. Ahora me enorgullece portar este nombre tan místico y sutil, de matices nahuas, de significados enigmáticos y profundos. Mi nombre me complementa, me socorre, me ilumina, me consuela, me fortalece, cómo no hacerlo si una Luna siempre irradia luz en medio de la oscuridad y con ella espera en el horizonte incierto un nuevo amanecer"3o

29.- Colaboración de Martha Karina Espinosa Gutiérrez

30.- Colaboración de Beu Ribe Yantlanesi Hernández Hernández, quien dentro de algunas lunas tendrá el 


\section{Testimonio 7}

"Me llamo Lupita Chamoy... Debo decir que contar el porqué de mi nombre me entusiasma mucho y esta historia está llena de detalles que son imposibles de contar de manera breve, pero trataré de simplificarla para poder contarlo todo. Fui la primera nieta mujer y todos mis primos, tíos, abuelos y, obvio. papás me esperaban con emoción, sin embargo esperaban a un varón, uno más a la familia Mirón y otro aún más a la Morales. A primera vista todo lucía normal, dicen que mi mamá nunca se vio más guapa, pero que desde el primer momento vomitó, parece que yo me empeñaba en molestarla y decir iESTOY AQUÍ NO LO OLVIDES! Básicamente éramos pobres, nuestra casa era quizás más pequeña que este salón y el dinero que mi padre había ganado en el programa de Pedro Ferriz, se había agotado por completo, así que para mi nacimiento no se compró nada, todo lo reciclé de mi hermano mayor y cuando digo todo lo es todo. Entonces programaron mi cesárea para el primero de diciembre, pero hacía frío y dijeron que no, luego que el dos y hacía aún más frío y así pasó el tres, el cuatro y el cinco, hasta que mi madre dijo: ino más, por favor sáquenlo de aquíi y sí, dijo sáquenlo, pobre ilusa que no contaba con el reto existencial que le estaba por llegar. Y así inició la cesárea, todo muy bien, hasta el momento en que el doctor dijo: ino es posible! Mi madre temiendo lo peor preguntó que qué pasaba, los doctores sonriendo y gritando, dijeron: ies niñai Mi madre desconfiada me observó y me aplastó de la emoción y bueno lo demás ya se lo imaginan. Ese día salió el sol más brillante del mes y mi papá y hermano, de escasos tres años, contaban la maravillosa historia de cómo pasé de varón a niña. Y fue precisamente mi hermano quien decidió que me llamaría así: Lupita. Después no hubo poder humano que me quitara ese nombre: mis abuelas lo apoyaron con insistencia, siempre dijeron que a mí me había enviado la virgen, cual Moisés en canasta, mis padres intentaron cambiarlo sin éxito alguno porque, desde la primera hora de nacida, ya todos me llamaban así y parece que a mí me gustaba. Sé que mi nombre es el más común que puede existir en México, 4 de cada 5 mujeres se llaman así y todos tienen una Lupita en su vida. Al principio era molesto, no podía escribirlo en el kínder y siempre cuando me llamaban otras 20 niñas volteaban también, pero conforme he ido creciendo me gusta más y ahora entiendo que lo de la canasta que decían mis abuelas tal vez no es tan irreal. Pero bueno aquí viene la segunda parte, a los 18 años tuve la peor depresión de todo el mundo (no exagero) y realmente quería 
dejar de ser yo, lo deseaba con todo mi ser, el dolor parecía tanto que me daba miedo confesarlo. Por razones demasiado dolorosas y dramáticas para esta clase tuve que cambiarme hasta el nombre, entonces busqué algo con lo que ocultarme, y fue cuando la encontré a ella, a Chamoy, tiene seis años y su lenguaje es rimbombante, es una muñeca de una marca que muchos llaman ridícula, pero que a mí me salvo la vida: en menos de un mes ya todos me llamaban Chamoy y a mí me gustaba. Ese personaje me ayudó a salir del dolor y, sobre todo, me enseño a perdonar, a perdonarme y fue así como comprendí que debía llamarme de las dos maneras: Lupita porque me eligió a mí y Chamoy porque yo lo elegí, entonces por fin, pude ser capaz de encontrar un balance en mi vida y dejar de esconderme, cabe mencionar que siempre fui cobarde. Mi vida ha sido poco más que caótica, cosas como la muerte y las espantosas malas noticias no me asustan, porque ya forman parte de mí, realmente soy el ser con la peor suerte del mundo y al mismo tiempo la sujeta más rica que pudieron conocer, es por ello que estos nombres tan comunes y, al mismo tiempo, complejos son la mejor forma de llamarme. Ahora ya todos me llaman Chamoy, dicen que hasta me queda mejor y tengo la ligera sospecha de que mis hijos me llamarán así. Ser Chamoy me trajo seguridad, pero ser Lupita me dio amor, ser Chamoy es divertido pero ser Lupita me trajo alegría, ser Chamoy me trajo amor, pero Lupita me ha hecho conservarlo. Así que me quedo con ambas, ambas se necesitan y una no existe sin la otra. Y bueno esta es la historia de mi nombre, del mejor nombre que pude haber tenido"

\section{Testimonio 8}

"El nombre de Úrsula viene de lejos, de tiempo atrás. Marisol conoció ese nombre cuando era una niña muy pequeña. Lo oyó venir de la boca de su abuelo Víctor. Él era un hombre grande, enorme, fuerte. Los otros nietos de Víctor se echaban a correr cuando lo veían, temiendo siempre una reprimenda, un mal rato. Pero Marisol nunca entendió el temor que su abuelo generaba en los otros niños. Para ella, Víctor fue siempre sinónimo de risas, de brincoteos por la casa, de consuelo y de abrazos. Marisol siempre guardó como un tesoro secreto esa satisfacción inexplicable que le daba ser tan acogida por su abuelo. Nunca entendió por qué su abuelo hacía con ella esas concesiones expresivas y afectivas que no prodigaba para el resto de los nietos. Pero no le importaba, porque ella lo único que quería era subirse al torbellino de la risa que su 
abuelo le daba cuando se encontraban. Marisol tampoco entendía por qué su abuelo, en las tarde de juego a las escondidas y al caballito la llamaba siempre 'iÚrsula!'. Nunca entendió por qué, pero nunca lo olvidó tampoco a pesar de su corta edad. El nombre se le quedó impreso en la piel y en la memoria. Úrsula fue nombrada así, desde el momento en que sus padres supieron que esperaban una niña. No hubo dudas, ni rodeos. El padre de la niña por nacer, había guardado la historia del abuelo Víctor. Así que al saber del advenimiento de una niña, el nombre de Úrsula emergió con naturalidad, espontáneamente. Cuando por fin el nacimiento de Úrsula fue dado a conocer a los seres cercanos y las preguntas sobre la elección del nombre emergían de sus amigos, Marisol sentía la necesidad de aclarar que el nombre de Úrsula no era un homenaje para el realismo mágico, sino un homenaje para su abuelo. Pero a fuerza de recordar las tardes de su niñez de donde provenía el nombre de su hija, los días de lluvia en la milpa, de olor a tierra mojada, de viento fresco jugando con su cara y los pasos enérgicos del abuelo persiguiéndola por los rincones, finalmente entendió que no hay nada que aclarar; pensó que es maravilloso que cada niño pueda anidar en su corazón su propio Macondo familiar y se sintió otra vez afortunada por esos pequeños enigmas de la vida que nos ayudan a recordar de dónde venimos"

\section{Comentario final}

Para terminar sólo queremos subrayar que detrás del nombre está lo que no se nombra: aquello considerado correcto o incorrecto, prestigioso o decadente, glorioso o infortunado, valioso o deplorable, noble o vergonzoso; virtuoso, digno y honroso, es decir, un cúmulo de valoraciones que conforman diversos y contrastantes significados culturales.

Cuando la madre o el padre dan el nombre también dan vivencias, experiencias, costumbres y un cúmulo de concepciones y creencias, aquello que es preciso recordar, reivindicar, enaltecer, honrar, celebrar, pero también lo que se debe olvidar, negar, despreciar o silenciar. Otros nombres preceden al nombre que nos dieron, con sus propias historias y los ecos de un pasado en el que otras voces confrontaron sus visiones del mundo. El nombre entonces está en la frontera entre lo individual y lo social, entre el yo y el otro, entre la memoria y el olvido. Se erige como signo, como aquella palabra primigenia con la que nos incorporamos a la vida social y cultural, como un samblaje en el que se unen y concentran 
circunstancias históricas, políticas, sociales y culturales que nos hablan de conflictos y contradicciones en torno a la identidad y el respeto a la diferencia.

La memoria de los otros con el cúmulo de representaciones e imaginarios construidos en el cruce de un tiempo y un espacio histórico y cultural, al condensarse en el nombre le adjudican una significación social. Esta significación moviliza nuestras posibilidades de interpretación $\mathrm{y}$, a veces, pone a prueba nuestra capacidad de asombro. Capacidad que, según Zemelman, está presente siempre que nos enfrentamos con la realidad y sin la cual resulta imposible construir conocimiento:

\footnotetext{
[...] la capacidad de asombro está necesariamente presente en el enfrentamiento con la realidad al que ha estado obligado el conocimiento analítico a lo largo de toda su historia. Precisamente, es a partir de las contradicciones que yacen en la inercia del saber acumulado de donde tendrá que resurgir el asombro, si es que queremos mantenernos alertas al conocimiento de lo inédito en la realidad [...] el conocimiento es el asombro vuelto sobre sí mismo, mientras que el asombro es el conocimiento como capacidad de salirse de sí mismo para rastrear las incertidumbres" (Zemelman, 1992: 167)
}

Con base en esa categoría metodológica, los autores de este artículo decidimos contestar también la interrogante de Borges, poner a prueba esa capacidad de salirse de sí mismo e intentar mirar las incertidumbres. El resultado de nuestras indagaciones está contenido en los siguientes testimonios que compartimos con los lectores a manera de despedida:

\section{Testimonio 1}

“"Norma la de Guadalajara', es el nombre del mambo que Dámaso Pérez Prado hizo famoso en los primeros años de la década de los sesenta y que se escuchaba en todas las estaciones de radio. Cuentan que una mañana lluviosa de febrero, mientras mi padre recorría en su volteo la carretera que comunica el rancho de los abuelos con la ciudad de Acayucan, encendió el radio y escuchó la célebre composición. El contrapunto entre la melodía de los clarinetes y la armonía de los saxofones, el ritmo de la conga, la presencia del cencerro marcando el tiempo y el grito característico del rey del mambo, conformaban una mezcla efusiva, gozosa y vital que contrastaba con la preocupación imperante en la casa de mis padres desde que, en la víspera, la doctora Villarreal había anunciado un complicado parto. Parto en el que nacería, un mes antes del término natural, la hija menor de los García Meza. En medio de ese contraste de sentimientos se decidió mi primer nombre, el segundo me fue dado para honrar la valentía y la fortaleza de mi madre durante los tormento- 
sos ocho meses que demoró el embarazo. Mi nombre tiene resonancias festivas, vestigios de la cultura popular y, también, huellas de las creencias, de los valores, de las preocupaciones y de las alegrías de la familia en cuyo seno nací”

\section{Testimonio 2}

"Yo sería el primogénito. El primer hijo varón en la línea de la familia paterna, por tanto en mí recaía la perpetuidad del apellido Domínguez, cosa que mi abuelo paterno, originario de San Andrés Tuxtla, Veracruz, valoraba muchísimo. Sin embargo, mis padres no querían ponerme Próspero como mi padre, ni tomar el nombre de mi abuelo Joaquín, no me llamarían Agustín como el abuelo materno, tampoco Mario del Ángel como hubiera correspondido a la versión masculina de los nombres de mi madre y de mi abuela materna, y tampoco Carmelo por honrar a la abuela paterna; nada de eso, mis padres habían tomado la determinación de ir contra la costumbre y elegir un nombre sin carga en la familia, uno que no repitiera ninguno de los citados en línea directa, pues consideraban que al que estaba por nacer había que darle la oportunidad de crecer sin sombras pasadas, formándose identidad por sí mismo. En aquel tiempo no existía la posibilidad de hacerse un ultrasonido, todo quedaba a la sorpresa del preciso momento. Estaba decidido entonces, si nacía hombre se llamaría Daniel, si nacía mujer se llamaría Martha, con ache. Mi madre Ángeles, a quien decimos de cariño Gela, afirma que escogieron el nombre, en principio, por su sonido, y porque Daniel en hebreo significa 'juicio de Dios'. No tenemos raíces hebreas en la familia, pero en el año 1961 de la era cristiana, ese argumento bastó. Fui el primero de seis hijos. La segunda en llegar fue Martha, apenas año y medio más tarde. No mucho tiempo después, la sorpresa fue doble, nació Joaquín David, entonces, en la misma sala de partos el médico dijo: 'madre, viene otro', cinco minutos después el llanto de María de los Ángeles trajo inesperada alegría. A los dos años llegó Próspero Alejandro. Con el nacimiento de los últimos tres hijos se hizo evidente que a mis padres les había dejado de importar repetir los nombres de ellos mismos, de la abuela materna y del abuelo paterno. Cuando yo tenía cuatro años cumplidos, en casa, ya éramos cinco hermanos. Pasaron seis años más para que llegara la fuera de serie, mi hermana Verónica, su nombre se lo debe a la influencia de un tío torero que apreciaba enormemente dicho pase taurino. El nombre decreta, así que con la asistencia de los Ángeles la familia Prosperó. En descargo de mi padre debo decir que no fue tan difícil 
convencer a mi madre de tener la media docena, era aceptable el número, después de todo, a ella le tocó ser la sexta de doce hermanos Cuenca. Pasaron los años, me casé con Mariana Vilchis y como era nuestro sueño tuvimos dos hijos: el primero fue varón, Diego, y dos años después nació Miranda Xiuh. Estaba asegurada la persistencia del linaje de los Domínguez, o eso creía porque, ahora que el mayor entró a la primaria, todos lo conocen como Diego Vilchis. Daniel es el nombre con el que me bautizaron, pero en realidad es sólo uno de los muchos que llevo sobre la piel. Toda la vida me la he pasado buscándome, construyendo mi propia identidad, a veces me encuentro y luego vuelvo a salir de viaje. Soy un navegante, yo soy: Galileo Mexica, Odiseo Jarocho, Cuen, Adán Pescador, Dramaturgo del Puerto, Cuenca, Dedecé, Cronopio, el Eslabón perdido y el Eslabón encontrado, la pieza que faltaba en la cadena de mi propio ser. Soy un híbrido. 'Y en el salado fui pez”'

El nombre se inscribe y nos inscribe en el territorio donde vive y palpita, incesante, la palabra: la que nos nombra y nos permite nombrar, la que guarda los ecos de otras vivencias, la que le da sentido al presente y al porvenir, la que nos hace ser y estar... la que nos convoca a buscar las piezas de los samblajes y asombrarnos con los hallazgos.

\section{Referencias bibliográficas}

Allende, Isabel, El cuaderno de Maya, Plaza y Janés, España, 2011. Bajtín, M., Yo también soy (fragmentos sobre el otro), Trad. Tatiana Bubnova, México, Taurus, 2000.

Estética de la creación verbal, Trad. Tatiana Bubnova, Siglo XXI, México. 1995.

Bajo Pérez, Elena, El nombre propio en español, Arco Libros, Madrid, 2008.

Banchs, María A., "Representaciones sociales, memoria social e identidad de género", en Akademos, vol. II, nº 1, 2000.

Benjamin, Walter, Discursos interrumpidos I. Filosofía del arte y de la historia, Prólogo, traducción y notas de Jesús Aguirre, Taurus, Argentina, 1989.

Borges, Jorge Luis, El otro, el mismo, en Obras Completas, Buenos Ai- 
res, Emecé, 1989, vol. II.

Bourdieu, Pierre, Razones prácticas sobre la teoría de la acción, Trad. Thomas Kauf, Anagrama, Barcelona, 1997.

Bubnova, Tatiana, "Bajtín en la encrucijada dialógica (datos y comentarios para contribuir a la confusión genera)”, en Bajtín y sus apócrifos, Iris M. Zavala (Coord.), Anthropos, España. 1996.

Cardenal, Ernesto, Nueva antología, Siglo XXI editores, $11^{\mathrm{a}}$. edición, México, 2002.

Deleuze, Gilles, "Lettre a M. Cressole”, en M-Cressole, Deleuze, ed. Universitario, París, 1973, citado por Miguel Morey, Gilles Deleuze, Lógica del sentido, prólogo de Miguel Morey, Paidós Surcos 10, Barcelona, 2005.

Del Palacio, Celia, Mujeres de la tormenta, Summa de Letras, México, 2012.

Escobar Villegas, Juan Camilo, Lo imaginario. Entre las Ciencias Sociales y la Historia, Cielos de arena, Medellín, 2000.

García Meza. Norma Esther, “Todos los nombres”, en Historias de Lectura II, Conaculta, México, 2005.

Giménez, Gilberto, Teoría y análisis de la cultura, Tomo Uno, Conaculta-Icocult, Colección intersecciones, México, 2005.

Estudios sobre la cultura y las identidades sociales, Conaculta-Iteso. México, 2007.

Grandes, Almudena, El corazón helado, TusQuets, Madrid, 2007.

Jelin, Elizabeth, Los trabajos de la memoria, Siglo XXI, Madrid, 2002.

Kraus, Arnoldo "Holocausto: memoria y tautología", en La Jornada Semanal, domingo 16 de febrero del 2003, núm. 415.

López Aguilar, Enrique, "Milena”, en La Jornada Semanal, Domingo 21 de enero de 2007, núm. 620.

Lotman, Iuri M., La semiosfera I. Semiótica de la cultura y del texto, Selección y traducción del ruso por Desiderio Navarro, Ediciones Cátedra, Madrid, 1996,

Majchrzak, Irena, "Alfabetización a partir del nombre propio", en Transatlántica de educación, No. 2, México, 2007.

Moliner, María, Diccionario de uso del español, prólogo Manuel Seco, Tercera edición, Gredos, España, 2007.

Moscovici, Serge, El psicoanálisis, su imagen y su público, Huemul, Buenos Aires, Argentina, 1979.

Monsiváis, Carlos, Los rituales del caos, Ediciones Era, México, 1995.

"Para un cuadro de costumbres. De cultura y vida cotidiana en los ochentas", en Cuadernos Políticos, número 57, Editorial 
Era, mayo-agosto de 1989, México.

Paz, Octavio, La estación violenta, Fondo de Cultura Económica, México, 1982.

Poniatowska, Elena, Fuerte es el silencio, Ediciones Era, $17^{\mathrm{a}}$. reimpresión, México, 2006.

Tinísima, Ediciones Era, México, 1992.

Ricoeur, Paul, "Definición de la memoria desde el punto de vista filosófico”, en ¿Por qué recordar?, Foro Internacional Memoria e Historia, Elie Wiesel, (Coord.), Ediciones Granica, España, 2002.

Tesone, Juan Eduardo, En las huellas del nombre propio. Lo que los otros inscriben en nosotros, Letra viva, Buenos Aires, 2009.

Voloshinov, N., El marxismo y la filosofía del lenguaje, Alianza Universidad, Madrid, 1993.

Zemelman, Hugo, Los horizontes de la razón, Tomo II, Anthrpos, Barcelona, 1992.

\section{Sitios de internet}

http://portales.mx.cervantesvirtual.com/servlet/SirveObras/p328/ (Consultado el 13 de septiembre de 2012).

www.elcaminodesandiego.com/ (Consultado el 10 de julio de 2012).

http://www.youtube.com/watch?v=8xPmlFHYfRQ (Consultado el $19 \mathrm{de}$ noviembre de 2012).

http://www.jornada.unam.mx/2006/02/o6/index.php? (Consultado el 13 de julio de 2012).

http://www.jornada.unam.mx/2005/01/18/a09n2esp.php (Consultado el13 de julio de 2012).

http://www.jornada.unam.mx/2007/05/10/index.php?section=estados\&article $=035$

(Consultado el 13 de julio de 2012).

http://www.jornada.unam.mx/2012/o9/02/politica/o17n1pol (Consultado el 2 de septiembre de 2012).

http://www.proceso.com.mx/?p=325915 (Consultado el 23 de noviem- 
bre de 2012).

http://www.rtve.es/alacarta/videos/cuentame-como-paso/cuentame-como-paso-t2-capitulo-40/882955/ (Consultado el 30 de noviembre de 2012).

https://www.youtube.com/watch?v=U14QEqaSF-Y (Consultado el 2 de septiembre de 2014).

https://www.youtube.com/watch?v=BcHZZLQcNok (Consultado el 2 de septiembre de 2014). 